\title{
Prediction of minimum fluidization velocity in pulsed gas-solid fluidized bed
}

\author{
Yanjiao $\mathrm{Li}^{1}$, Chenyang Zhou ${ }^{2}$, Guannan $\mathrm{Lv}^{2}$, Yongxin Ren ${ }^{2}$, Yuemin Zhao ${ }^{2}$, Qingxia Liu ${ }^{3}$, \\ Zhonghao Rao ${ }^{2}$, and Liang Dong ${ }^{2}$ \\ ${ }^{1}$ Affiliation not available \\ ${ }^{2}$ China University of Mining and Technology \\ ${ }^{3}$ University of Alberta
}

May 6, 2020

\begin{abstract}
Abstract: Fluidized bed technology plays a vital role in petrochemistry and coal separation. To enhance fluidization stability, the flow is periodically introduced into the gas-solid fluidized bed to form a pulsed gas-solid fluidized bed. As the main fluidization parameter, the minimum fluidization velocity (umf) can reflect the change of the critical state of particles in the pulsed gas-solid fluidized bed, directly affecting the study of two-phase distribution in the bed. Due to lack of theoretical study on umf in pulsed gas-solid fluidized bed, the work proposed a novel method to predict umf comibined with soft sphere model. Meanwhile, the spring-damping and the resonance force models were established under the action of pulsating airflow. A theoretical model of umf was then derived for pulsed gas-solid fluidized bed based on experimental stress analysis of particles. The novel correlation is basically agreement with almost available data in the literatures and present work.
\end{abstract}

\section{Hosted file}

manuscript . docx available at https : //authorea. com/users/319044/articles/448835-prediction-ofminimum-fluidization-velocity-in-pulsed-gas-solid-fluidized-bed

\section{Hosted file}

figure.docx available at https://authorea.com/users/319044/articles/448835-prediction-ofminimum-fluidization-velocity-in-pulsed-gas-solid-fluidized-bed 